DOI: 10.20472/EFC.2019.011.009

\author{
PAWEL KLIBER \\ Poznan University of Economics, Poland
}

\author{
ANNA RUTKOWSKA-ZIARKO \\ University of Warmia and Mazury, Poland
}

\title{
AN ALGORITHM FOR CONSTRUCTION OF A PORTFOLIO WITH A FUNDAMENTAL CRITERION
}

\begin{abstract}
:
The classical models for construction of investment portfolio do not take into account fundamental values of considered companies. In our approach we extend the portfolio choice by adding this dimension to the classical criteria of profitability and risk. It is assumed that an investor selects stock according to their attractiveness, measured by some fundamental values of companies. In this approach portfolios are assessed according to three criteria: their profitability, risk (measured by variance of returns) and fundamental value (measured by some indicators of fundamental value). In this article we consider earnings to price ratio as the measure of the fundamental value of a company. In the paper we consider an algorithm for constructing portfolios with fundamental criterion based on analytical solutions for appropriate optimization problems. In the optimization problem we consider minimizing variance with constrains on expected return and attractiveness of investment, measured with some indicators of fundamental values of companies in a portfolio. We also present empirical examples of calculating effective portfolios of stocks listed on the Warsaw Stock Exchange.
\end{abstract}

\section{Keywords:}

portfolio analysis, fundamental value, multicriterial choice, fundamental analysis

JEL Classification: C61, C63, G11 


\section{Introduction}

Classical methods for selecting portfolio of investments, developed by Markowitz (1952, 1959) and Sharpe (1963), take into account only market performance of companies measured by changes in their prices. In the classical model potential portfolios of investment are evaluated according to two criteria: profitability and risk. The first criterion is measured with expected rate of return and the second one with variance or standard deviation of return. One does not consider any other criteria, which can give some additional information about the future prospects of the company or market situation of its shares.

However in the recent years there was a growing interest in the methods of portfolio analysis in which one considers alternative ways of constructing portfolio. The article of Kolm, Tütüncü and Fabozzi (2014) contains a survey of major developments in portfolio theory since the beginning of its existence and the book of Doumpos and Zopounidis (2014) lay the attention on multicritera methods used in this field. Most of innovations depends on using some criteria of risk other than variance or standard deviation of returns, as for example semivariance or conditional value at risk. The article of Fabozzi, Focardi and Jonas (2007) presents the variety of risk measures that are currently used in practice of portfolio investments. In some other approaches some characteristics of distributions of returns are assets are used as additional criteria for evaluating portfolio performance. Examples of such characteristics can be skewness or kurtosis. Such extended portfolio analysis is presented in (Briec, Kerstens and Jokund, 2007) or (Rodríguez, Luque and González, 2011).

There are several research in which one considers criteria that are not based on assets' returns. There is a branch of the literature which takes into account ethical, social or environmental criteria in portfolio construction. The so-called socially responsible investments approach was described for example in (Steuer, Qi and Hirschberger 2007). The articles (Ballestero et al. 2012) and (Bilbao-Terol et al. 2013) are another examples of this approach.

Lo, Petrov and Wierzbicki (2003) considered liquidity of stocks as an additional criterion in the portfolio construction process. There are only a few papers which considers also fundamental values of companies. Xidonas, Mavrotas and Psarras (2010) considered the amount of dividends paid by companies. Jacobs and Levy (2013) in their paper take into account the risk associated with leverage. The utility function of an investor includes the costs of margin calls, which can force borrowers to liquidate securities at adverse prices due to illiquidity, losses exceeding the capital invested, and the possibility of bankruptcy.

Tarczyński (2002) applied a synthetically developed measurement to evaluate the economic and financial standing of a company and used this measure as an additional criterion for evaluation possible portfolios. He called this measure the taxonomic measure 
of attractiveness of investment (TMAl). The portfolio constructed with the use of this measure was called fundamental portfolio. In recent years this model was modified for example by substituting variance as a measure of risk by semi-variance (RutkowskaZiarko and Garsztka 2014). In (Rutkowska-Ziarko 2013) the Mahalanobis distance was used to determine the TMAI, due to a possible correlation between diagnostic financial variables.

In this paper we propose an approach in which one uses price-earnings ratio as a measure of fundamental value of companies in a portfolio. We present a simple algorithm for constructing a fundamental portfolio with price-earnings fraction as an additional criterion for evaluating portfolios. The algorithm is based on analytical solutions of optimization problems. In the empirical part we verify this method computing fundamental portfolios of the stocks traded on the Warsaw Stock Exchange. The article is organized as follows. After this introduction, in the section 2 we present our proposition of extending classical portfolio theory for additional, fundamental criterion. Section 3 provides analytical solutions to the problems connected with computing fundamental portfolios and algorithm for constructing such portfolios. Section 4 contains empirical examples from the Warsaw Stock Exchange and section 5 concludes.

\section{Portfolio problem with criterion on price-earnings ratio}

In the article we use a generalization of classical Markowitz model of portfolio optimization, see (Markowitz 1952) and (Markowitz 1959). We consider an investor who tries to determine optimal composition of his portfolio. Assume that there are $n$ risky assets with random rates of returns $R_{1}, \ldots, R_{n}$. Let $\mu_{i}$ be an expected return of asset $i: \mu_{i}=E\left[R_{i}\right]$. By $\operatorname{cov}_{i j}$ we denote covariance between the asset $i$ and $i, \operatorname{cov}_{i j}=\operatorname{cov}\left(R_{i}, R_{j}\right)$. By $x_{i}$ we denote the proportion of wealth invested in the asset $i$. As in the classical Markowitz model an investor evaluates a portfolio according to criteria of expected rate of return and risk. The expected return equals

$\mu_{p}=\sum_{i=1}^{n} x_{i} \mu_{i}$

and the risk is measured by the variance of return from portfolio, which equals

$\sigma_{p}^{2}=\sum_{i=1}^{n} \sum_{j=1}^{n} x_{i} x_{j} \operatorname{cov}_{i j}$.

The expected return and variance of return of portfolio's components are estimated on the basis of historical returns of the shares of companies. The problem of portfolio selection thus relies entirely on the past market data. In our approach we combine this classical approach to estimating future market performance with the fundamental analysis. It augments Markowitz model with a third criterion which describe financial and economic standing of companies which shares are in a portfolio. 
Market multiples are financial indicators that compere given accounting values per share with the market price of this share. Loughran and Wellman (2011) analysed a broad sample of not financial firms from NYSE, AMEX, NASDAQ. They found that companies with low levels of market multiples appeared to have higher stock returns than companies with high levels of market multiples.

Price to earnings ratio $(\mathrm{P} / \mathrm{E})$ is one of the most popular market multiples Price to earnings ratio $(P / E)$ relates earnings per one ordinary share to its market price:

$$
\mathrm{P} / \mathrm{E}=\frac{\text { market price of } \text { a share }}{\text { net profit per share }} \text {. }
$$

It is considered that the $\mathrm{P} / \mathrm{E}$ ratio can give valuable information about the future profability of investments. The research on the pricing anomalies connected with the price to earnings ratio dates back to the work of Breen (1968). He considered US companies from S\&P 500 in 1953-1966 period. He discovered that portfolios of companies with the lowest P/E ratio were more profitable for investors. This phenomenon was called earnings effects. Similar results were obtained for NYSE by Basu $(1977,1983)$.

Price to earnings ratio anomaly is still the topic of interest in the field of finance. Chaya and Nigam (2015) analysed 500 the most liquid companies listed on Bombay Stock Exchange (BSE). They found that it is possible to get abnormal returns on capital markets for investing in companies with low value of price to earnings ratio. They termed this phenomenon as value premium. The term value premium relates to others market multiples as well. Troung (2009) discovered that low P/E stocks outperform high P/E stocks in New Zealand. Ikoku, Hosseini and Okany (2010) examined the information value of price-earnings $(\mathrm{P} / \mathrm{E})$ ratios in the Nigerian stock exchange prediction of stock prices.

Since the of $P / E$ has a role in predicting future stock prices, this ratio can be used in the portfolio selection problem. Richie (1992) proposed the strategy of buying stocks of companies with low value of P/E ratio, e.g. out of three or four first deciles. This strategy and these similar ignore the risk analysis and diversification of portfolio. We combined the fundamental strategy based on the P/E ratio with risk analysis in the context of Markowitz portfolio theory. Instead of price to earnings ratio the reciprocal of this ratio was used in the portfolio chose model. We used earnings to price ratio (EP), calculated as in equation below:

$$
\mathrm{EP}=\frac{\text { net profit per share }}{\text { market price of } a \text { share }} \text {. }
$$

We used E/P ratio in multicriteria portfolio selection problem. We assume that it is good for investors to buy the stocks of companies with a high level of net income per share compare to its market price. The EP as an additive measure. It can be shown that the ratio of earnings of all companies in a portfolio (proportional to number of shares in the portfolio) divided by the value of the portfolio is a weighted average of earnings to price ratios of all companies in this portfolio. In other words earnings to profit ratio of any portfolio $\left(E P_{p}\right)$ is given by

$$
E P_{p}=\sum_{i=1}^{n} x_{i} E P_{i} \text {, }
$$

where $E P_{1}, \ldots, E P_{n}$ are earnings to profit ratios of single companies. 
With the introduction of $E P_{p}$ we have three criteria for assessing an investment: profitability, risk and fundamental value. The formulas for calculating these criteria are given in Eqs. 1-2 and Eq. 7. One of the methods for obtaining a portfolio which is efficient with respect to all three criteria is to solve a problem of minimizing variance of a portfolio with constrains on the two other criteria. This leads to the following optimization problem:

$$
\text { minimize } \sum_{i=1}^{n} \sum_{j=1}^{n} x_{i} x_{j} \operatorname{cov}_{i j}
$$

with respect to

$$
\sum_{i=1}^{n} x_{i} \mu_{i} \geq \gamma
$$

and

$$
\sum_{i=1}^{n} x_{i} E P_{i} \geq E P_{y} \text {, }
$$

where $\gamma$ is the target rate of return and $E P_{\gamma}$ is the fundamental value of portfolio required by the investor. Of course, there is an additional condition that $\sum_{i=1}^{n} x_{i}=1$.

\section{The analytical solution of the portfolio problem}

Let $\Sigma$ be a covariance matrix of returns, i.e.

$$
\Sigma=\left[\begin{array}{ccc}
\operatorname{cov} v_{11} & \cdots & \operatorname{cov} v_{1 n} \\
\vdots & \ddots & \vdots \\
\operatorname{cov} v_{1 n} & \cdots & \operatorname{cov} v_{n n}
\end{array}\right] .
$$

Define the following vectors: $\mu=\left(\mu_{1}, \ldots, \mu_{n}\right)^{T}, z=\left(E P_{1}, \ldots, E P_{n}\right)^{T}$ and let $e$ be a column vector of length $n: e=(1, \ldots, 1)^{T}$. Using the vector notation, the optimization problem (4)-(6) can be formulated as follows:

$$
\text { minimize } \frac{1}{2} x^{T} \Sigma x
$$

with respect to

$$
\begin{aligned}
& x^{T} e=1, \\
& x^{T} \mu \geq \gamma
\end{aligned}
$$

and

$$
x^{T} z \geq E P_{y} \text {. }
$$

The Kuhn-Tucker conditions for the problem (7)-(9) are as follows

$$
\Sigma x=\lambda_{1} e+\lambda_{2} \mu+\lambda_{3} z \text {, }
$$

where $\lambda_{2}, \lambda_{3} \geq 0$, with the complementary conditions

$$
\begin{aligned}
& \lambda_{2}\left(x^{T} \mu-\gamma\right)=0, \\
& \lambda_{3}\left(x^{T} z-E P_{y}\right)=0 .
\end{aligned}
$$

Assuming that covariance matrix is nondegenerate (as it is in practical usages), it follows from eqn. (11) that the solution has the following form: 


$$
x=\lambda_{1} \Sigma^{-1} e+\lambda_{2} \Sigma^{-1} \mu+\lambda_{3} \Sigma^{-1} z .
$$

We have to consider several cases. To simplify the notation, we define the following symbols. Let

$$
\begin{aligned}
& g_{11}=e^{T} v^{1}, g_{12}=e^{T} v^{2}, g_{13}=e^{T} v^{3}, g_{22}=\mu^{T} v^{2}, \\
& g_{23}=\mu^{T} v^{3}, g_{33}=z^{T} v^{3},
\end{aligned}
$$

where

$$
v^{1}=\Sigma^{-1} e, \quad v^{2}=\Sigma^{-1} \mu, \quad v^{3}=\Sigma^{-1} z .
$$

Firstly, assume that $\lambda_{2}=\lambda_{3}=0$. From complimentary condition (12) and (13) it turns out that only condition (8) must be satisfy as equality. Putting the solution (11) with $\lambda_{2}=\lambda_{3}=0$ into (8) we obtain the solution

$$
\tilde{x}^{1}=\frac{1}{g_{11}} \Sigma^{-1} e .
$$

The minimal variance in this case equals

$$
\sigma_{1}^{2}=\frac{1}{g_{11}^{2}}
$$

In the case when $\lambda_{2}>0, \lambda_{3}=0$, in the optimal solution condition (8) is fulfilled and condition (9) holds as an equation, which gives a system of equations

$$
\begin{aligned}
& \lambda_{1} g_{11}+\lambda_{2} g_{12}=1, \\
& \lambda_{1} g_{12}+\lambda_{2} g_{22}=\gamma .
\end{aligned}
$$

After some manipulations one can write the solution of this system as

$$
\tilde{x}^{12}=\left(1-\alpha_{12}\right) \tilde{x}^{1}+\alpha_{12} \frac{v^{2}}{g_{12}},
$$

where

$$
\alpha_{12}=\frac{g_{12}\left(\mathrm{rg}_{11}-g_{12}\right)}{g_{11} g_{12}-g_{12}^{2}} .
$$

The variance of the portfolio in this solution equals $\sigma_{12}^{2}=\sigma_{1}^{2}+\Delta \sigma_{12}^{2}$, where

$$
\Delta \sigma_{12}^{2}=\frac{\left(y g_{11}-g_{12}\right)^{2}}{g_{11}} \text {. }
$$

The case $\lambda_{2}=0, \lambda_{3}>0$, is analogic to the last one. The optimal solution satisfies conditions (8) and (10) as equations. The solution can be expressed as

$$
\tilde{x}^{13}=\left(1-\alpha_{13}\right) \tilde{x}^{1}+\alpha_{13} \frac{v^{g}}{g_{18}},
$$

where

$$
\alpha_{13}=\frac{g_{18}\left(E P_{\gamma} g_{11}-g_{18}\right)}{g_{11} g_{s 8}-g_{18}^{2}} .
$$

The growth of variance when switching from $\tilde{x}^{1}$ to $\tilde{x}^{13}$ equals

$$
\Delta \sigma_{13}^{2}=\frac{\left(E P_{\gamma} g_{11}-g_{18}\right)^{2}}{g_{11}} \text {. }
$$


In the last remaining case is when $\lambda_{2}>0, \lambda_{3}>0$. In this case all conditions (8)-(10) must be fulfilled as equalities, which brings us to the following system of equations

$$
\lambda G=a,
$$

where $\lambda$ is the vector of multipliers $\lambda=\left(\lambda_{1}, \lambda_{2}, \lambda_{3}\right)^{T}, a=\left(1, \gamma, E P_{Y}\right)^{T}$ and the matrix $G$ is

$$
G=\left[\begin{array}{lll}
g_{11} & g_{12} & g_{13} \\
g_{12} & g_{22} & g_{23} \\
g_{13} & g_{23} & g_{33}
\end{array}\right] .
$$

The optimal solution to the problem (4)-(7) with all conditions fulfilled as equation can be thus formulated as follows:

$$
\tilde{x}^{123}=\lambda_{1} v^{1}+\lambda_{2} v^{2}+\lambda_{3} v^{3}, \text { where } \quad \lambda=G^{-1} a .
$$

These derivations lead to the following algorithm for finding the optimal solution of the problem (4)-(6):

1. Compute the vector $\tilde{x}^{1}$ and check if it fulfills the conditions (5) and (6). If so, it is the optimal solution.

2. Otherwise, calculate $\Delta \sigma_{12}^{2}$ and $\Delta \sigma_{13}^{2}$. Choose the smaller value: let it be $\Delta \sigma_{1 k}^{2}$.

Compute the vector $\tilde{x}^{1 k}$ and check if it fulfills the conditions (5) and (6). If so, it is the optimal solution. Otherwise the optimal solution is the vector $\tilde{x}^{123}$.

\section{Empirical results}

In the empirical part we analyze 20 largest and most liquid companies listed on the Warsaw Stock Exchange. The sample includes all companies form WIG20. The computations are based on quarterly returns calculated on daily closing prices in the period starting from the beginning of 2014 and ending at 5 March 2019. Returns are computed as relative increases of prices according to the formula:

$r_{i t}=\frac{P_{\text {it }+8}-P_{\text {it }}}{P_{\text {it }}} \cdot 100 \%$,

where $r_{i t}$ is the rate of return on security $i$ at time $t, s$ is the length of investment horizon (in our case one quarter) expressed in days and $P_{i t}$ is the quoted price of security $i$ at time $t$.

Financial indicators for each company were calculated based on annual financial reports for 2018. For each company in the sample we computed taxonomic measure of attractiveness of investment. Mean return and standard deviations were calculated based on time series of returns. Table 1 contains information concerning profitability, risk and price to earnings ratio for all companies. 
Table 1: Profitability, risk, price-earnings ratios (P/E) and earning-price ratios (EP)

\begin{tabular}{|l|r|r|r|r|}
\hline Company & Mean (\%) & $\begin{array}{c}\text { Standard } \\
\text { deviation (\%) }\end{array}$ & \multicolumn{1}{c|}{ P/E } & EP \\
\hline ACP & 0.21 & 0.01 & 5.92 & 0.169 \\
\hline ALR & 0.29 & 8.94 & 10.02 & 0.100 \\
\hline BZW & 0.51 & 16.05 & 14.63 & 0.068 \\
\hline CCC & 0.24 & 10.64 & 29.57 & 0.034 \\
\hline CPS & 5.62 & 14.43 & 17.34 & 0.058 \\
\hline ENA & 1.49 & 8.88 & 3.95 & 0.253 \\
\hline ENG & -1.06 & 13.04 & 5.40 & 0.185 \\
\hline EUR & -1.06 & 17.66 & -116.71 & -0.009 \\
\hline KGH & -2.11 & 14.67 & 12.27 & 0.081 \\
\hline LPP & 1.21 & 19.89 & 30.98 & 0.032 \\
\hline LTS & 1.37 & 16.14 & 6.12 & 0.163 \\
\hline MBK & 3.79 & 16.73 & 16.57 & 0.060 \\
\hline OPL & -0.04 & 11.62 & -105.40 & -0.009 \\
\hline PEO & -2.59 & 12.36 & 12.38 & 0.081 \\
\hline PGE & -1.84 & 8.92 & 7.32 & 0.137 \\
\hline PGN & -2.24 & 12.39 & 12.36 & 0.081 \\
\hline PKN & 2.34 & 13.89 & 5.35 & 0.187 \\
\hline PKO & 5.98 & 14.75 & 16.80 & 0.060 \\
\hline PZU & 0.69 & 11.19 & 8.76 & 0.114 \\
\hline TPE & -3.75 & 24.88 & 2.97 & 0.336 \\
\hline
\end{tabular}

Source: own calculations

During the period under research period, there were only two companies with negative earnings: EUR and OPL. For companies with positive earnings the P/E ratio was the lowest for TPE. At the same time, this company was the company with the highest risk and its expected return was negative. The lowest standard deviation was for the ACP and the P/E ratio for this company was positive and quite low. The EP ratio of companies was negatively correlated with the mean returns (correlation coefficient -0.254 ) and there was no correlation between standard deviation of return and EP ratio (correlation coefficient 0.033). There was also no correlation between mean return and risk measured with variance (correlation coefficient -0.035).

The problem of portfolio choice in this situation is a trade-off between risk and two other criteria. We seek for the portfolio which minimizes risk, but low-risk portfolios tend to have lower expected return. On the other hand, if we assume higher requirements on mean return of a portfolio, the solution will have lower EP. Figure 1 depicts the efficient frontier for the three-criteria portfolio choice. Each point on the graph represents a solution for the problem (4)-(6) for different combination of required mean return and required level of EP. 
Figure 1: Effective frontier for the portfolio problem with three criteria

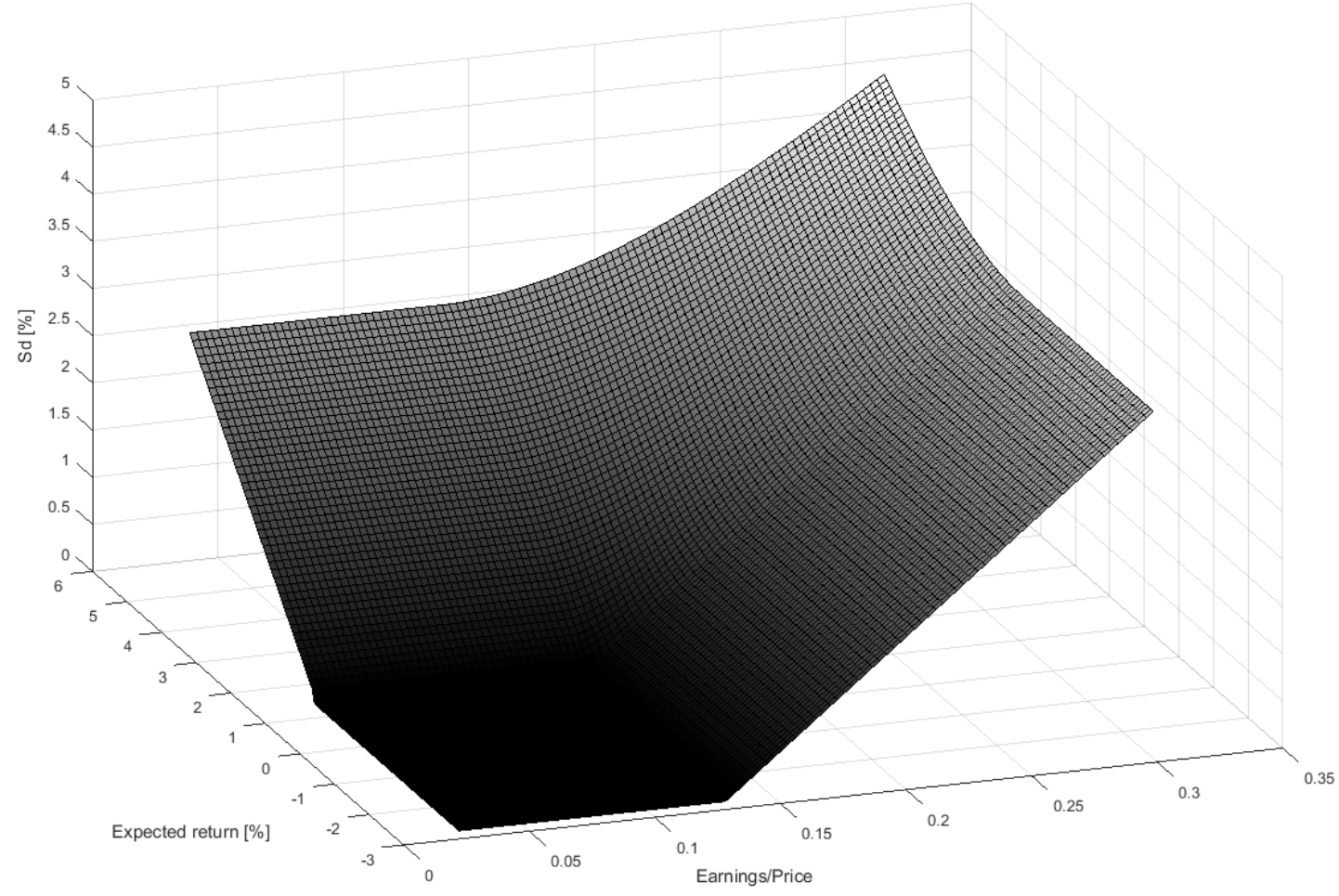

Source: own study

To analyze the impact of fundamental values of companies in which one is willing to invest on the trade-off between profitability and risk, we determined the shape of efficient frontiers for various values of the required EP ratio. We calculated, using algorithm proposed in section 3, effective portfolios for $E P_{y}$ at the levels of $0.06,0.18$ and 0.27 . The results are depicted at Figure 2. As one can see, the higher levels of required earnings-price ratio moves the effective frontier upwards. For low levels of required EP ratio, as the required profitability of expected return grows, the restriction connected with EP ratio (given by eqn. 6 ) is less important and for the highest levels of expected rate of return it is not binding. This phenomenon is expressed on the figure by convergence of effective frontiers on the right side of the plot. However when required EP ratio is high enough the restriction on EP becomes binding for any value of expected return, which moves classical efficient frontier much upwards. This shift of efficient frontier illustrates the trade-off between assessment of a portfolio measures by market measures and its fundamental value. 
Figure 2: Effective frontiers for different values of earnings-price ratio

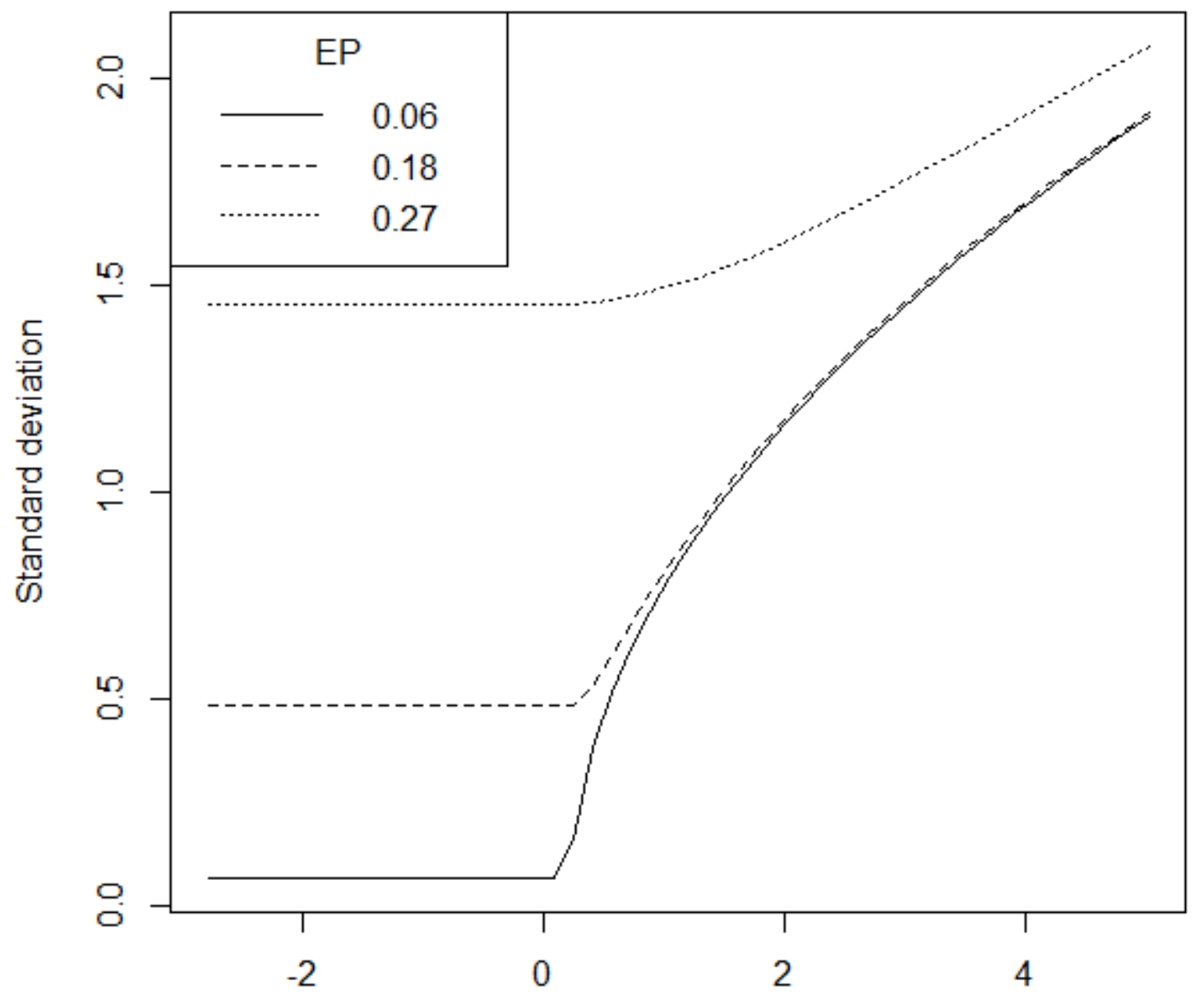

Expected Return

Source: own study

\section{Conclusions}

In the paper we propose an algorithm for constructing a portfolio of assets, for which three criteria is considered: profitability (measured with expected return), risk (measured with variance of returns) and a fundamental value of companies in the portfolio (measured with price to earnings ratio). The algorithm for finding effective portfolios with respect to all three criteria is based on analytical solutions of optimization problems. We have shown that the algorithm is effective and allows one to construct efficient portfolios with minimal computational effort.

The proposed algorithm allow us to determine the effective frontier (i.e. the tradeoff between profitability and risk) for several level of requirements concerning fundamental values of companies which stocks are in the portfolio. The results from empirical research for the major companies traded on the Warsaw Stock Exchange reveals that if an 
investor requires high expected return from his portfolio, then the constrain on fundamental value is not binding.

\section{Reference}

BALL R. (1992) The Earnings-Price Anomaly. Journal of Accounting and Economics. Vol. 15, pp. 319-345.

BALLESTERO, E.; BRAVO, M.; PEREZ-GLADISH, B.; ARENAS-PARRA, M.; PLA-SANTAMARIA, D. (2012) Socially Responsible Investment: a Multicriteria Approach to Portfolio Selection Combining Ethical and Financial Objectives. European Journal of Operational Research. Vol. 216, pp. 487-494.

BASU S. (1977) Investment Performance of Common Stocks in Relation to Their Price-earnings Ratios: A Test of the Efficient Market Hypothesis. Journal of Finance. Vol. 3, pp. 663-682.

BILBAO-TEROL, A.; ARENAS-PARRA, M.; CAÑAL F.; BILBAO-TEROL, C. (2013) Selection of Socially Responsible Portfolios Using Hedonic Prices. Journal of Business Ethics. Vol. 115, pp. 515-529.

BASU, S. (1977) Investment Performance of Common Stocks in Relation to Their Price-Earnings Ratios: A Test of the Efficient Market Hypothesis. Journal of Finance, Vol. 32, pp. 663-682.

BASU, S. (1983) The relationship between earnings' yield, market value and return for NYSE common stocks: Further evidence. Journal of Financial Economics. Vol. 12, pp. 129-156.

BREEN, W. (1968) Low Price-Earnings Ratios and Industry Relatives. Financial Analysts Journal. Vol. 24, pp. $125-127$.

BRIEC,W.; KERSTENS, K.; JOKUND, O. (2007) Mean-Variance-Skewness Portfolio Performance Gauging: A General Shortage Function and Dual Approach. Management Science. Vol. 53, pp. 135149.

CHHAYA, G.; NIGAM, P. (2015) Value Investing with Price-Earnings Ratio in India. The IUP Journal of Applied Finance. Vol. 21, pp. 34-48.

DOUMPOS, M.; ZOPOUNIDIS, C. (2014) Multicriteria Analysis in Finance. Springer, Heidelberg, New York.

FABOZZI, F.J., FOCARDI, S., JONAS, C. (2007) Trends in Quantitative Equity Management: Survey Results. Quantitative Finance. Vol. 7, pp. 115-122.

IKOKU, A.; HOSSEINI, A.; OKANY, C. (2010) Can Price-Earnings Ratio Predict Stock Prices? Evidence from the Nigerian Equity Market. The International Journal of Finance. Vol. 22, pp. 6581-6611.

JACOBS, B.; LEVY, K. (2013) Leverage aversion, efficient frontiers, and the efficient region. Journal of Portfolio Management. Vol. 39, pp. 54-64.

KOLM, P.; TÜTÜNCÜ, R.; FABOZZI, F. (2014) 60 Years of Portfolio Optimization: Practical Challenges and Current Trends. European Journal of Operational Research. Vol. 234, pp. 356-371.

LO, A.; PETROV, C.; WIERZBICKI, M. (2003): Its 11pm-Do You Know Where Your Liquidity Is? The Mean-Variance-Liquidity Frontier. Journal of Investment Management. Vol. 1, pp. 55-93.

LOUGHRAN, T.; WELLMAN, J. (2011) New evidence on the relation between the enterprise multiple and average stock returns. Journal of Financial and Quantitative analysis. Vol. 46, no. 6, pp 1629-1650.

MARKOWITZ, H. (1952) Portfolio selection. Journal of Finance, 7:77-91.

MARKOWITZ, H. (1959) Portfolio Selection: Efficient Diversification of Investments. John Wiley and Sons, New York.

RICHIE J. (1992) The Fundamentals of Fundamental Analysis,. Probus Professional Publisher.

RODRÍGUEZ, R.; LUQUE, M.; GONZÁLEZ, M. (2011) Portfolio Selection in the Spanish Stock Market by Interactive Multiobjective Programming. TOP. Vol. 19, pp. 213-231. 
RUTKOWSKA-ZIARKO, A. (2013) Fundamental portfolio construction based on Mahalanobis distance. In: Algorithms from and for Nature and Life, Studies in Classification, Data Analysis, and Knowledge Organization. Springer International Publishing Switzerland, pp. 417-426.

RUTKOWSKA-ZIARKO A.; GARSZTKA P. (2014) Diversification of risk of a fundamental portfolio based on semi-variance. Poznań University of Economics Review. Vol. 14, pp. 80-96

SHARPE, W.F. (1963) A simplified model for portfolio analysis. Management Science. Vol. 9, pp. 277-293.

STEUER, R.; QI, Y.; HIRSCHBERGER, M. (2007) Suitable-portfolio investors, nondominated frontier sensitivity, and the effect of multiple objectives on standard portfolio selection. Annals of Opererations Research. Vol. 152, pp. 297-317.

TARCZYŃSKI, W. (2002) Portfel fundamentalny papierów wartościowych [Fundamental Portfolio of Assets]. Polish Economic Editorial Office (PWE). Warsaw. [in Polish]

TROUNG, C. (2009) Value Investing Using Price Earnings Ratio in New Zealand. University of Auckland Business Review. Vol. 11, pp. 1-7.

XIDONAS, P.; MAVROTAS, G.; PSARRAS, J. (2010) Equity Portfolio Construction and Selection Using Multiobjective Mathematical Programming. Journal of Global Optimization. Vol. 47, pp. 185-209. 